\title{
LA REGULACIÓN DEL DERECHO DE ALIMENTOS EN LA UNIÓN EUROPEA
}

\section{REGULATION OF MAINTENANCE OBLIGATIONS IN THE EUROPEAN UNION}

\author{
Rosa Lapiedra Alcamí \\ Universidad de Valencia. España/Spain \\ rosa.lapiedra@uv.es
}

Recibido/Received: 27/01/2015

Aceptado/Accepted: 27/04/2015

\section{RESUMEN}

El trabajo aborda una de las cuestiones más relevantes hoy en día en el marco de las relaciones familiares a nivel internacional. En efecto, el constante movimiento transfronterizo de personas implica inevitablemente un aumento de las relaciones familiares mixtas. Ello, a su vez, provoca un incremento de los conflictos de carácter familiar. De hecho, la inmensa mayoría de los casos, las reclamaciones de alimentos a nivel transfronterizo tienen su origen en un procedimiento de divorcio o separación judicial. $\mathrm{Si}$ a todo ello le unimos el nuevo marco económico surgido de la crisis económica global que estamos atravesando llegamos a la conclusión que el número de reclamaciones alimenticias a nivel mundial es muy elevado y de ahí la enorme relevancia de este trabajo.

\section{PALABRAS CLAVE}

Derecho de familia, normativa europea, alimentos. Derecho internacional privado.

\section{SUMARIO}

I. Importancia práctica del derecho de alimentos. II. El Reglamento 4/2009: ámbitos de aplicación. III. Competencia judicial internacional en materia de alimentos. IV. La determinación del derecho aplicable a las obligaciones alimenticias. V. Reconocimiento y ejecución de resoluciones judiciales. Bibliografía.

\begin{abstract}
The work deals with one of the most important issues today in the context of family relationships from the international point of view. Indeed, the constant movement of people inevitably implies a rise in mixed family relationships. This, in turn, causes an increase in family conflicts character. In fact, the vast majority of cases, maintenance claims across borders originate in proceedings for divorce or legal separation. If to all this we add the new economic framework arising from the global economic crisis we are experiencing we conclude that the number of complaints worldwide food is very high, hence the great relevance of this work.
\end{abstract}

\section{KEYWORDS}

Family law, European regulations, maintenance, private international law.

\section{CONTENTS}

I. Practical importance of maintenance obligations. II. Regulation 4/2009: fields of application. III. International jurisdiction on maintenance obligations. IV. Applicable law to the maintenance obligations. V. Recognition and enforcement of judgments. References. 


\section{IMPORTANCIA PRÁCTICA DEL DERECHO DE ALIMENTOS}

Históricamente, se ha admitido de forma generalizada en todos los sistemas la posibilidad de que aquellas personar que carezcan de recursos para satisfacer sus necesidades más básicas puedan reclamar una pensión en concepto de alimentos de sus parientes más próximos.

La importancia práctica del derecho a la prestación de alimentos en nuestro país resulta innegable teniendo en cuenta el constante aumento de los flujos migratorios que tienen España como destino. Qué duda cabe que este constante movimiento transfronterizo de personas implica inevitablemente un aumento de las relaciones familiares mixtas. Y ello, a su vez, provoca un incremento de los conflictos de carácter familiar. De hecho, la inmensa mayoría de los casos, las reclamaciones de alimentos a nivel transfronterizo tienen su origen en un procedimiento de divorcio. Es precisamente como consecuencia de la ruptura del vínculo matrimonial cuando uno de los ex cónyuges solicita alimentos al otro -SAP de Vizcaya, de 24 de febrero de 2011 (TOL 2212.777), SAP de Madrid, de 10 de mayo de 2012 (TOL 2652.642), SAP de Barcelona, de 21 de junio de 2012 (TOL 2608.427), SAP de Asturias, de 5 de julio de 2012 (TOL 2610.872), o bien uno de los progenitores los reclama en favor de los hijos, SAP de Huesca, de 29 de enero de 2007 (TOL 1063.085), SAP de Madrid, de 11 de octubre de 2010 (TOL 2018.279), SAP de Barcelona, de 2 de junio de 2011 (TOL 2204.835).

Este elevado número de conflictos obliga a determinar la competencia judicial internacional, así como el régimen jurídico aplicable a este tipo de litigios de naturaleza transfronteriza en el ámbito familiar.

\section{EL REGLAMENTO 4/2009: ÁMBITOS DE APLICACIÓN}

Un elemento decisivo en la evolución de la regulación del derecho de alimentos en España deriva de su condición de Estado miembro de la Unión Europea. En las últimas décadas, se ha producido una intensa actividad legislativa del legislador europeo, con la aprobación de diversos instrumentos que otorgan una regulación desde el punto de vista del Derecho internacional privado para casos conectados con la Unión Europea. En este sentido, en el seno de la Unión Europea se ha elaborado el Reglamento 4/2009 del Consejo, de 18 de diciembre de 2008, relativo a la competencia judicial, la ley aplicable, el reconocimiento y la ejecución de las resoluciones judiciales y la cooperación en materia de obligaciones de alimentos. Los objetivos más importantes de este Reglamento consisten en garantizar una igualdad de trato a todos los acreedores de alimentos y, además, asegurar un cobro rápido y eficaz de los créditos alimenticios.

Esta normativa no sólo prevalece sobre las regulaciones de origen nacional, sino que además, el régimen previsto en este Reglamento abarca casi todas las hipótesis posibles, de ahí que prácticamente sustituye las normas de Derecho internacional privado estatales en materia de alimentos, quedando éstas últimas con un carácter meramente residual. En consecuencia, y como veremos, las normas europeas resultarán aplicables no sólo a ciudadanos europeos sino también a todos aquellos nacionales de terceros Estados que se encuentren domiciliados en el territorio de algún Estado miembro de la Unión Europea.

Varios son los aspectos importantes que podemos destacar de este instrumento de regulación. Por un lado, es de señalar que engloba las tres cuestiones básicas y clásicas del derecho internacional privado, a saber, competencia judicial internacional, la ley aplicable y 
el reconocimiento y la ejecución de resoluciones judiciales. Junto a ello, añade algunas disposiciones en materia de cooperación entre autoridades para facilitar que la prestación de alimentos en el ámbito transnacional se haga efectiva (art. 49-63). Asimismo, el Reglamento se ocupa del derecho a la justicia gratuita (art. 44 a 47) y, a tal efecto, se establece que no podrán imponerse condiciones más restrictivas en los procedimientos internacionales que en los internos equivalentes (art. 44.4).

Conviene determinar, con carácter previo, los diferentes ámbitos de aplicación del Reglamento a efectos de poder concretar en qué supuestos actuará. Así, desde la perspectiva territorial, el Reglamento se aplica en el territorio de los 27 Estados miembros de la Unión Europea incluido Reino Unido e Irlanda. Sin embargo, por lo que respecta a Dinamarca presenta algunas peculiaridades en cuanto que se aplicará parcialmente, tal y como se podrá observar a lo largo de este trabajo. (Esplugues Mota, 2014:463).

Por lo que se refiere al ámbito de aplicación temporal, es de señalar que la entrada en vigor de este instrumento estaba prevista para el 18 de junio de 2011, a tenor de lo dispuesto en su artículo 76. Sin embargo, el mismo precepto condiciona la entrada en vigor en la mencionada fecha a que resulte aplicable el Protocolo de la Haya de 2007. Tal es así que afirma que, de no darse esta circunstancia, el Reglamento se aplicará a partir de la fecha de aplicación de dicho Protocolo en la Unión Europea (art. 76).

En efecto, la entrada en vigor del Reglamento 4/2009 ha planteado algunos problemas en la práctica, si bien referidos únicamente al ámbito de la ley aplicable. Ello es debido a que esta norma institucional no establece una regulación específica o propia en materia de ley aplicable a alimentos, sino que hace una remisión a lo dispuesto en el Protocolo de la Haya de alimentos de 2007. Es por ello que, la efectiva aplicación de esta normativa europea dependía, a su vez, de la entrada en vigor del Protocolo elaborado en el seno de la Conferencia de la Haya de Derecho internacional privado, a saber, el Convenio de la Haya sobre cobro internacional de alimentos para niños y otros miembros de la familia, de 23 de noviembre de 2007 y el Protocolo complementario de la misma fecha relativo a la ley aplicable. Ambos instrumentos fueron elaborados con el objeto de simplificar y modernizar el régimen jurídico aplicable en materia de alimentos, pues la existencia de varios instrumentos convencionales unido al hecho de que no todos los Estados Miembros eran parte añadía un elemento más de complejidad (Viarengo, 2007:234).

En previsión de que llegara la fecha prevista de entrada en vigor del Reglamento, (18/06/2011) sin que el Protocolo de 2007 en materia de alimentos fuera aplicable, el Consejo emitió una Decisión el 30 de noviembre de 2009 relativa a la adhesión de la Unión Europea al Protocolo de La Haya, de 23 de noviembre de 2007, sobre la Ley aplicable a las obligaciones alimenticias. En virtud del art. 4 de la mencionada Decisión, la Unión Europea declara que aplicará las normas establecidas en el Protocolo de 2007 con carácter provisional a partir del 18 de junio de 2011 por ser la fecha de aplicación del Reglamento (CE) n. 4/2009 del Consejo, de 18 de diciembre de 2008, y todo ello con independencia de que dicho Protocolo no hubiese entrado en vigor en esa fecha de conformidad con su artículo 25, apartado 1.

En relación al ámbito de aplicación personal, es de señalar que el criterio de la nacionalidad no se tiene en cuenta a efectos de aplicar la normativa europea, por lo que operará con independencia de que la nacionalidad de las partes sea la de un Estado miembro o de un tercer Estado, lo determinante será el domicilio de las partes -SAP de Valencia, de 26 de marzo de 2012 (TOL 2569.957), SAP de Barcelona, de 30 de noviembre de 2010 (TOL 2061.918), SAP de Barcelona, de 21 de junio de 2012 (TOL 2608.427). 
Por lo que al ámbito de aplicación material se refiere, se aplica a todas las reclamaciones de alimentos derivadas de una relación familiar, de parentesco, matrimonio o afinidad, tal y como dispone el artículo 1.1. El Reglamento no incluye una definición de alimentos, sin embargo, opta por una interpretación autónoma (Considerando 11). Es por ello que resulta necesario tener en cuenta los criterios de interpretación seguidos por la jurisprudencia del TJUE relativos al Convenio de Bruselas de 1968 así como al Reglamento 44/2001 en relación con esta materia. En este sentido, opta por un concepto amplio de alimentos incluyendo, asimismo, la pensión compensatoria entre los cónyuges tras un procedimiento de divorcio o separación judicial.

Desde la perspectiva de los posibles acreedores y deudores de alimentos, es de señalar que en los últimos años han aparecido nuevos posibles sujetos cuya inclusión en el concepto de acreedor y deudor está ocasionando un debate importante en algunos países (Espinosa Calabuig, 2007:128). Nos referimos a los denominados step parents, o bien, a los hijos ya sean biológicos, adoptados o fruto de otra relación de uno de los miembros de la pareja de hecho homosexual. En estos casos, la doctrina se muestra favorable a realizar una interpretación amplia del concepto de acreedor y deudor de alimentos $\mathrm{y}$, por ende, entenderlos incluidos igualmente (Espinosa Calabuig, 2009:63) Si bien es cierto, que corresponderá al ordenamiento jurídico aplicable a cada caso el que en última instancia determine el alcance y límites de estos nuevos sujetos.

\section{COMPETENCIA JUDICIAL INTERNACIONAL EN MATERIA DE ALIMENTOS}

\section{III.1. Foros de competencia judicial internacional en el Reglamento 4/2009}

La efectiva aplicación de este Reglamento supone, desde la perspectiva de la competencia judicial internacional, que el Reglamento determina la jurisdicción competente de los Estados miembros de la Unión Europea en materia de alimentos sustituyendo las disposiciones contenidas en materia de alimentos en el Reglamento 44/2001, en concreto en su artículo 5.2.

El Reglamento incorpora una amplia variedad de foros de competencia judicial internacional. Tal es así, que cubren casi todas las hipótesis que se puedan plantear en la práctica para cualquier conflicto transnacional. De ahí que la aplicación del régimen estatal previsto en la LOPJ será muy reducida o inexistente (Esplugues Mota, 2014:465). En concreto, recoge por un lado, el foro de la autonomía de la voluntad (art. 4 y 5), por otro, y para el caso en que las partes no hayan hecho uso de esta libertad prevé unos foros generales de carácter alternativo (art. 3). Junto a estos incorpora, asimismo, un foro subsidiario (art. 6) y un forum necessitatis (art. 7). Todo ello sin olvidar la norma de competencia judicial internacional prevista para la adopción de medidas provisionales y cautelares (art. 14).

\section{III.1.1. Foro de sumisión expresa y tácita}

Por lo que se refiere al foro de la autonomía de la voluntad, es de señalar que el Reglamento prevé en los artículos 4 y 5 respectivamente, la posibilidad de que las partes realicen un pacto de sumisión tanto expreso como tácito en favor de unos determinados tribunales de Estados miembros. Sin embargo, la autonomía de la voluntad de las partes no se establece en términos absolutos, como ocurre en el Reglamento 44/2001 respecto de la materia contractual, sino que está limitada. Ello se debe precisamente a la especial naturaleza de este tipo de conflictos. 
En relación con el pacto de sumisión expresa, se exige que el acuerdo entre las partes conste por escrito, si bien, no será necesario que figure en un único documento. De ahí que se admitirá como válido cualquier intercambio de escritos por mecanismos electrónicos entre las partes con la única condición de que quede constancia un registro duradero del acuerdo. A efectos de ejercer esta autonomía de la voluntad, las partes podrán elegir el Tribunal del Estado miembro que estimen conveniente, si bien esta posibilidad de elección queda reducida a una lista cerrada prevista expresamente por el legislador europeo en el artículo 4. Fuera de las opciones recogidas en el mencionado precepto no cabrá ejercer esta libertad. Sin embargo, esta posibilidad de sumisión expresa queda excluida cuando en el conflicto en materia de alimentos esté implicado un menor de 18 años (art. 4.3).

En definitiva, las partes van a poder realizar un pacto de sumisión expresa pudiendo elegir de entre una de las siguientes opciones (art. 4): a) el órgano jurisdiccional del Estado miembro en que una de las partes tenga su residencia habitual (art. 4.1.I.a); b) El órgano u órganos jurisdiccionales del Estado miembro del que sea nacional una de las partes (art. 4.1.I.b), c) O, en relación específicamente, con las obligaciones de alimentos entre cónyuges o ex cónyuges (art. 4.1.I.c) a su vez va a poder optar entre: i) el órgano jurisdiccional competente para conocer de sus litigios en materia matrimonial, esto es, aquellos previstos en el Reglamento 2201/2003 o ii) el órgano jurisdiccional del Estado miembro en cuyo territorio hayan tenido su última residencia habitual común los cónyuges durante al menos un año.

El Reglamento también aborda la posibilidad de que las partes pacten expresamente la sumisión a los tribunales de Estados que se encuentren vinculados por el Convenio de Lugano de 2007. En tal caso, la competencia de los Tribunales de estos países vendrá determinada por las normas de competencia judicial internacional allí previstas (art. 23 y 24, 2, 5.2 y 31), excepto para aquellos litigios en los que se encuentre involucrado un menor de 18 años (art. 4.4 in fine) (Parra Rodríguez, 2010:280).

Sin embargo, cuando se trata de la sumisión tácita de las partes, no parece existir limitación alguna. Tal es así que, de conformidad con el artículo 5, resultará competente el tribunal del Estado miembro ante el que el demandante hubiese interpuesto la demanda, siempre que el demandado realice a posteriori cualquier acto procesal que no sea el de impugnar la competencia. Llama la atención que en el caso de la sumisión tácita de las partes no se recoge la limitación relativa a los menores de 18 años.

\section{III.1.2. Foros de carácter alternativo}

A falta de voluntad de las partes, ya sea expresa o tácita, acerca del órgano competente en materia de alimentos debemos acudir a los foros generales previstos en el artículo 3. Estos criterios generales de competencia son alternativos, de ahí que el demandante pueda optar entre interponer la demanda ante alguno de los siguientes órganos jurisdiccionales, siempre que se trate, por supuesto, de Estados miembros de la Unión Europea: a) El órgano jurisdiccional del lugar donde el demandado tenga la residencia habitual; b) El órgano jurisdiccional del lugar donde el acreedor tenga su residencia habitual; c) El órgano jurisdiccional competente en virtud de la ley del foro para conocer de una acción relativa al estado de las personas, cuando la demanda relativa a una obligación de alimentos sea accesoria de esta acción, salvo si esta competencia se basa únicamente en la nacionalidad de una de las partes; y finalmente, d) El órgano jurisdiccional competente en virtud de la ley del foro para conocer de una acción relativa a la responsabilidad parental (Reglamento 2201/2003), cuando la demanda relativa a una obligación de alimentos sea accesoria de esta acción, salvo si esta competencia se basa únicamente en la nacionalidad de una de las partes. 
La inclusión de los dos últimos foros de competencia judicial internacional c) y d) resulta lógica, y ello por varios motivos. Por un lado, por razones de economía procesal. Y, por otro, en relación al primero de los supuestos, lo cierto es que el mismo juez que está conociendo del proceso de divorcio o separación judicial será el que en mejores condiciones se encuentre para determinar si corresponde o no una pensión en concepto de alimentos y así es como se suele hacer en la práctica, -SAP de Vizcaya, de 24 de febrero de 2011 (TOL 2212.777), SAP de Madrid, de 18 de marzo de 2011 (TOL 2182.071), SAP de Valencia, de 26 de marzo de 2012 (TOL 2569.957)-. Debe recordarse que la pensión compensatoria entre los ex cónyuges también se entendía incluida en el concepto de alimentos.

De igual modo, es de señalar la especial vinculación que habitualmente existe entre las acciones relativas a la responsabilidad parental con los litigios relativos a la pensión de alimentos respecto de un menor -d)-. Es por ello que, el mismo juez que se pronuncie acerca del litigio en materia de derechos de custodia y visita del menor esté perfectamente legitimado para determinar la necesidad de conceder una pensión de alimentos en favor del mismo. De hecho, es lo que también se suele hacer en la práctica, -SAP de Valencia, de 10 de noviembre de 2011 (TOL 2366.928), SAP de Valencia, de 10 de noviembre de 2011 (TOL 2366.928)-. Piénsese, además, que los foros previstos en el Reglamento 2201/2003 atienden fundamentalmente al interés superior del menor, de ahí que se asegure y proteja al máximo el derecho del menor a la prestación de alimentos (Espinosa Calabuig, 2007:127).

\section{III.1.3. Foros especiales}

Junto a los foros generales que terminamos de ver, el Reglamento prevé un foro de carácter subsidiario (art. 6) para aquellos supuestos en que, de conformidad con los criterios de competencia judicial internacional del Reglamento 4/2009 que ya se han analizado, no resulte competente ningún tribunal de un Estado miembro, ni tampoco resulten competentes los Tribunales de algún Estado vinculado al Convenio de Lugano de 2007 según lo dispuesto en el mismo. En estas circunstancias, resultarán competentes los órganos jurisdiccionales del Estado miembro de la nacionalidad común de las partes. Parece ser que el objetivo último de esta norma es la de excluir la aplicación de las normas de competencia judicial internacional internas o estatales (Esplugues Mota, 2014:465).

A continuación, el Reglamento incorpora un forum necessitatis (art. 7) previsto excepcionalmente para aquellos supuestos en que concurran las siguientes circunstancias. Por un lado, que en aplicación de los distintos foros previstos en el Reglamento (sumisión expresa o tácita, foros generales y foro subsidiario) ningún tribunal de algún Estado miembro se declare competente. Y, por otro lado, debe darse la circunstancia de que resulte imposible acudir a los tribunales del país con el que el litigio guarde una estrecha vinculación, por ejemplo, por encontrarse el país en guerra civil (Considerando 16). En estas circunstancias, se permite, de forma excepcional y a efectos de evitar una posible denegación de justicia, que los tribunales de algún Estado miembro puedan conocer del litigio, si bien se exige como condición que exista una conexión suficiente con el Estado miembro cuyos tribunales van a conocer. La cuestión relativa a la "conexión suficiente" deberá ser valorada por el juez atendiendo a las circunstancias de cada caso concreto (Pocar et al, 2009: 806).

Para finalizar, el art. 14 regula la posibilidad de solicitar medidas provisionales y cautelares. En este sentido, atribuye competencia a cualquier tribunal de los Estados miembros para que, a instancia de parte, puedan ordenar este tipo de medidas de conformidad con su ley interna y todo ello con independencia de que sea el juez de otro Estado miembro el que está conociendo del fondo del asunto. 
Qué duda cabe que la prestación de alimentos por su propia naturaleza puede estar sujeta a modificaciones debido a una modificación de las circunstancias acontecida con posterioridad a su concesión. Ya sea por un cambio en la capacidad económica del deudor de los alimentos o en las necesidades del acreedor de los mismos (Carballo Piñeiro et al., 2001:475). Es por ello que el Reglamento también se ocupa de esta cuestión en su artículo 8 fijando una serie de límites al ejercicio de la competencia judicial internacional.

\section{LA DETERMINACIÓN DEL DERECHO APLICABLE A LAS OBLIGACIONES ALIMENTICIAS}

La entrada en vigor del Reglamento 4/2009 supone la inaplicación de las normas de Derecho internacional privado españolas en la materia, en concreto, el artículo 9.7 del Código civil español.

El Reglamento 4/2009 no solamente regula la competencia judicial internacional, sino que como se ha visto con anterioridad también se ocupa del ámbito del derecho aplicable a las obligaciones alimenticias. Si bien, en este caso no ha fijado un régimen específico, sino que como ya se ha adelantado, remite a las soluciones contenidas en el Protocolo de la Haya de 2007 sobre la ley aplicable a las obligaciones alimenticias, tal y como se dispone expresamente en su artículo 15. A continuación, pasaremos a analizar la regulación contenida en el mismo.

\section{IV.1. El Protocolo de la Haya de 2007: ámbitos de aplicación}

Con carácter previo, concretaremos los diferentes ámbitos de aplicación de este instrumento para, a continuación, determinar el régimen jurídico aplicable que prevé en materia de alimentos. Desde la perspectiva de la materia regulada, el Protocolo de 2007 tiene como objetivo determinar la ley aplicable a las obligaciones derivadas de una relación de familia, filiación, matrimonio o afinidad, incluyendo las obligaciones alimenticias en favor de un niño con independencia de la situación conyugal de sus padres (art. 1.1 del Protocolo). Sin embargo, la aplicación del Protocolo no prejuzga, en ningún caso, la existencia de tales relaciones. Tal es así que, la existencia de las mencionadas relaciones familiares vendrá regulada por el ordenamiento jurídico de cada Estado.

Por lo que se refiere al ámbito de aplicación territorial, es de señalar que se aplica en el territorio de todos los Estados miembros de la UE, incluyendo Reino Unido e Irlanda. No obstante, no resultará aplicable a Dinamarca por cuanto que en virtud del Acuerdo entre la Unión Europea y Dinamarca la materia de la ley aplicable quedaba excluida (Pocar et al., 2009: 809). Desde la perspectiva temporal, la aplicación de sus normas se produce a partir del 18 de junio de 2011, tal y como se ha visto con anterioridad.

En relación a su ámbito de aplicación personal, el Protocolo tiene una eficacia universal, tal y como dispone su artículo 2. En consecuencia, los jueces de los Estados miembros de la Unión Europea, a excepción de las autoridades danesas, lo aplicarán siempre y en todo caso con independencia de la nacionalidad y el domicilio de las partes involucradas en la relación. De ahí que resulte, asimismo aplicable a las reclamaciones de alimentos en que se encuentren involucrados nacionales de terceros Estados que se hallen domiciliados en algún Estado miembro. Tal es así que, la ley designada en virtud del Protocolo de 2007 se aplicará aunque no sea la de un Estado miembro. De todo ello deriva que, la entrada en vigor de este instrumento ha supuesto para España la derogación de las normas de derecho internacional 
privado tanto convencional, como estatal en la materia. En concreto, resultan inaplicables tanto el Convenio de la Haya de 1973 sobre ley aplicable a las obligaciones alimenticias, como el artículo 9.7 del código civil español.

\section{IV.2. Ley aplicable en materia de alimentos}

A la hora de determinar la ley aplicable en materia de alimentos, es de señalar que el Protocolo incorpora un conjunto de normas conflictuales variadas. En primer lugar, reconoce autonomía de la voluntad a las partes para que puedan elegir el derecho aplicable (art. 8). Junto a esta posibilidad y a falta de elección, contiene unas soluciones de carácter general (art. 3). Y, finalmente, añade unas reglas especiales para supuestos concretos (art. 4 y 5).

\section{IV.2.1. Autonomía de la voluntad de las partes}

En relación a la autonomía de la voluntad de que disponen el acreedor y el deudor para elegir la ley aplicable a las obligaciones alimenticias debe reseñarse que no es absoluta, sino que presenta algunas limitaciones, como veremos a continuación. Así, en primer lugar, atribuye a las partes la posibilidad de designar en cualquier momento la ley aplicable a las obligaciones alimenticias. Sin embargo, esta libertad de elección queda reducida a alguna de las opciones previstas expresamente por el legislador (art. 8.1 del Protocolo). De ahí que puedan elegir entre alguna de la siguientes opciones: a) La ley de un Estado del cual sea nacional alguna de las partes en el momento de la designación; b) la ley del Estado de la residencia habitual de una de las partes, en el momento de la designación; c) La ley elegida por las partes para regir sus relaciones patrimoniales, o la ley efectivamente aplicada a tales relaciones o bien, d) la ley elegida por las partes para regir su divorcio, separación de cuerpos, o la ley efectivamente aplicada a tal divorcio o separación.

El acuerdo en virtud del cual las partes eligen la ley aplicable a las obligaciones alimenticias deberá constar por escrito o estar registrado en algún soporte cuyo contenido resulte accesible para su ulterior consulta (art. 8.2 del Protocolo).

En segundo lugar, y al igual que ocurre con las normas sobre competencia judicial previstas en el Reglamento, no será posible ejercer esta autonomía de la voluntad cuando las obligaciones alimenticias sean referidas a menores de 18 años, o mayores de edad que tengan algún tipo de discapacidad psíquica (art. 8.3).

En tercer lugar, existe otra limitación a esta posibilidad de elección, si bien en realidad constituye una cautela, por cuanto que la ley elegida por las partes no se aplicará cuando conlleve consecuencias manifiestamente injustas para cualquiera de las partes. A menos que, en el momento de la designación de la ley aplicable, las partes fueran debidamente informadas y conscientes de las consecuencias derivadas de la ley designada (art. 8.5).

Finalmente, y también con el objeto de proteger a la parte débil de la relación, se prevé en el artículo 8.4 que la posibilidad para el acreedor de renunciar a su derecho a alimentos no vendrá determinada por la ley elegida por las partes, sino por la ley de la residencia habitual del acreedor de los mismos.

\section{IV.2.2. Ley aplicable a falta de elección}

A falta de elección por las partes, el Protocolo prevé una solución de carácter general, en virtud de la cual las obligaciones alimenticias se regirán por la Ley del Estado en que el acreedor tenga su residencia habitual, salvo que el Protocolo disponga otra cosa (art. 3.1). Junto a esta regla general, el legislador ha previsto en el párrafo $2^{\circ}$ del artículo 3 el denominado conflicto móvil. De este modo, en caso de cambio en la residencia habitual del 
acreedor de los alimentos se aplicará la ley del Estado de la nueva residencia habitual a partir del momento en que se haya realizado dicho cambio.

A continuación, el Protocolo recoge en el artículo 4 dos reglas especiales para situaciones particulares, de ahí que se apliquen con preferencia a la regla general. La primera de las reglas especiales, se refiere a las obligaciones alimenticias "de los padres a favor de los hijos", "de los hijos a favor de los padres" y "de personas distintas de los padres a favor de personas que no hayan alcanzado la edad de 21 años". En tales casos, el legislador prevé la aplicación de la ley del foro en dos supuestos. El primero de ellos, cuando el acreedor no pueda obtener alimentos del deudor en virtud de la ley prevista según la regla general, esto es, según la ley de la residencia habitual del acreedor (art. 4.2). Y, el segundo supuesto, será cuando el acreedor haya acudido a la autoridad competente del Estado de la residencia habitual del deudor. Salvo que, con arreglo a esta última ley el acreedor no pudiera obtener alimentos, en cuyo caso se procederá a aplicar la ley de la residencia habitual del acreedor (art. 4.3).

En la hipótesis que el acreedor no pudiera obtener alimentos de conformidad con las reglas que terminamos de ver, el artículo 4.4 prevé la aplicación de la ley de la nacionalidad común del acreedor y deudor.

La segunda de las reglas especiales, se recoge en el artículo 5 y hace referencia a las obligaciones alimenticias entre cónyuges, ex-cónyuges o entre personas cuyo matrimonio haya sido anulado. En estas situaciones, la regla general (art. 3 del Protocolo) no se aplicará si una de las partes se opone y se da la circunstancia de que la ley de otro Estado presenta una vinculación más estrecha con éste, en cuyo caso deberá aplicarse ésta última. En particular, el legislador se refiere a la ley del Estado de la última residencia habitual común del matrimonio (art. 5).

\section{RECONOCIMIENTO Y EJECUCIÓN DE RESOLUCIONES JUDICIALES}

Con el fin de garantizar un cobro rápido y eficaz de los créditos alimenticios, como objetivo último de este Reglamento, se ha eliminado, por un lado y como regla general, el exequatur (art. 17.1). Y, por otro lado, establece que, la existencia de una resolución ejecutiva en materia de alimentos implicará necesariamente la adopción de las medidas cautelares que se estimen oportunas para evitar que pueda frustrarse el cumplimiento de la misma (art. 18).

A la hora de regular el reconocimiento y ejecución de este tipo de resoluciones, el Reglamento 4/2009 ha introducido un régimen distinto dependiendo de que la resolución judicial de alimentos haya sido dictada en un Estado miembro vinculado por el Protocolo de la Haya de 2007 (Sección 1 del Capítulo IV R. 4/2009) o, por el contrario, se trate de un Estado no vinculado por el mencionado Protocolo (Sección 2 del Capítulo IV). Si bien, también ha fijado un conjunto de reglas comunes y, por ende, aplicables en ambos casos.

\section{V.1. Resolución dictada por un Estado parte en el Protocolo de la Haya 2007}

Cuando se trate de una resolución judicial dictada por un Estado parte en el Protocolo de la Haya, el reconocimiento y el exequatur de la resolución judicial serán automáticos, esto es, sin necesidad de procedimiento alguno (Art. 17.1). En concreto, la eliminación del exequatur constituye una realidad para todas aquellas resoluciones judiciales en materia de alimentos que hayan sido dictas por tribunales de algún Estado miembro, con la excepción de 
Dinamarca. En consecuencia, las resoluciones judiciales dictadas en el territorio de cualquier Estado miembro, salvo Dinamarca, constituirán títulos directamente ejecutables en el resto de los países miembros de la Unión Europea.

Por lo que se refiere a la documentación que debe aportarse a efectos de solicitar la ejecución de la resolución en otro país, el artículo 20.1 señala que deberá presentar, por un lado, una copia de la resolución que reúna las condiciones necesarias para establecer su autenticidad (art. 20.1 a). Junto a ésta, deberá adjuntar asimismo, un extracto de la resolución expedida por el órgano jurisdiccional de origen, de acuerdo con el formulario que figura en el anexo I (art. 20.1 b)). Por lo que se refiere a la traducción del mencionado formulario, es de señalar que sólo deberá acompañarse una traducción cuando el idioma en el que esté redactado no sea una de las lenguas oficiales del Estado requerido (art. 20.1.d)). Finalmente, y cuando corresponda, deberá aportarse un documento que establezca el estado de los atrasos en la prestación de alimentos e indique la fecha en que se efectuó el cálculo (art. $20.1 \mathrm{c}$ )).

Una vez presentada toda la documentación necesaria ante el órgano correspondiente, la autoridad competente del Estado donde se pretende hacer efectiva la resolución judicial, deniegue o suspenda total o parcialmente la ejecución de la misma en base a unos motivos tasados expresamente por el legislador. Motivos que difieren según se trate de una denegación o una suspensión, si bien en ambos casos debe tramitarse a instancia del deudor. De este modo, la denegación tan sólo se podrá realizar en virtud de alguno de los motivos previstos expresamente por el legislador europeo en el artículo 21.

Por lo que se refiere a los motivos de denegación de la ejecución son los siguientes: en primer lugar, cuando el derecho a obtener la ejecución de la resolución haya prescrito, ya sea de conformidad con el Derecho de origen de la sentencia, ya sea de acuerdo al Derecho del Estado donde se pretende hacer efectiva (art. 21.2). En segundo lugar, en el caso de que la resolución judicial resulte incompatible con otra dictada, ya sea en el Estado de ejecución o en un tercer Estado pero con posibilidades de ser reconocida y ejecutada en el Estado de ejecución. A tal efecto, no se considerará resolución incompatible aquella que tenga por objeto modificar una resolución dictada con anterioridad debido a un cambio de circunstancias (art. 21.2 in fine) (Michinel Álvarez, 2002:665).

Los motivos en virtud de los cuales el juez podrá declarar la suspensión total o parcial de la ejecución son dos y están recogidos en el párrafo $3^{\circ}$ del artículo 21 del Reglamento. El primero de ellos refiere al supuesto en que se haya interpuesto ante el órgano jurisdiccional competente del Estado miembro de origen una solicitud de revisión de la resolución. Y, el segundo, vendría ocasionado por el hecho de que se suspenda la fuerza ejecutiva de la resolución extranjera en el Estado miembro de origen.

\section{V.2. Resolución dictada por un Estado no vinculado por el Protocolo de la Haya 2007}

La situación, sin embrago, difiere cuando se trata de resoluciones que provienen de Estados no vinculados por el mencionado Protocolo, tal es el caso de Dinamarca, el exequatur no ha sido eliminado (art. 26). En consecuencia, se prevé un reconocimiento automático de las decisiones y un procedimiento de exequatur similar al previsto en el Reglamento 44/2001. El procedimiento a seguir, documentación a presentar, plazos para resolver concediendo o no el exequatur y recursos contra esta decisión están previstos en los artículos 27, 28, 30 y 32 , respectivamente.

Siguiendo la misma línea que su antecesor el Reglamento 44/2001 y casi en los mismos términos, recoge en el artículo 24 los motivos en virtud de los que podrá denegarse el reconocimiento. A saber, en primer lugar, que la sentencia sea contraria al orden público del Estado de ejecución. En segundo lugar, cuando la sentencia se haya pronunciado vulnerando 
los derechos de defensa del demandado. En tercer lugar, cuando la resolución sea incompatible con otra dictada con anterioridad en el Estado miembro donde se solicita el reconocimiento. Y, en cuarto y último lugar, cuando la resolución fuere inconciliable con otra dictada con anterioridad en cualquier otro Estado miembro o en un tercer Estado siempre que exista identidad de objeto de causa y de partes y, además, dicha resolución reuniera las condiciones necesarias para ser reconocida en el Estado donde se pretende el reconocimiento.

\section{V.3. Reglas comunes}

Finalmente, y si bien hemos visto que el Reglamento prevé una regulación distinta dependiendo del Estado de origen de la sentencia, lo cierto es que contiene un conjunto de reglas comunes aplicables en ambos casos. Esto es, tanto si la resolución proviene de un Estado parte en el Protocolo de la Haya, como si ha sido dictada por un Tribunal no vinculado por el Protocolo, esto es, por un tribunal danés. En concreto, estas reglas son las siguientes: por un lado, se recoge la posibilidad de que el tribunal que ha dictado la sentencia otorgue fuerza ejecutiva con carácter provisional a la sentencia, aun cuando se haya interpuesto un recurso contra ella (art. 39). Por otro lado, fija un procedimiento común para aquellos casos en que se invoque en un Estado miembro una resolución judicial en materia de alimentos dictada en cualquier otro Estado parte. Junto a esta regla, se establece, asimismo, y al igual que el Reglamento 44/2001, que el procedimiento de ejecución en sentido estricto se regirá, siempre y en todo caso, por el derecho interno del país de la ejecución (art. 41.1). A continuación, prohíbe una revisión del fondo del asunto en el Estado de la ejecución. En efecto, el reconocimiento y ejecución no constituyen una nueva instancia, de ahí que no se pueda entrar a valorar el contenido de la decisión judicial. Y, finalmente, precisa que el cobro de alimentos tendrá prioridad sobre los costes ocasionados por la aplicación de este Reglamento.

Para concluir, debe señalarse que en materia de alimentos, con el objeto de garantizar un cobro rápido y eficaz de los créditos alimenticios, resulta imprescindible fijar un mecanismo seguro y efectivo de cooperación entre las autoridades de los diferentes Estados miembros (Borrás Rodríguez, 2008:136). Es por ello que el Reglamento contiene un conjunto de reglas bajo la rúbrica "cooperación administrativa entre autoridades centrales", donde se establece que cada Estado deberá designar una Autoridad Central que, con carácter general será la encargada de hacer de intermediaria para dar cumplimiento a las obligaciones impuestas por este Reglamento (art. 49.1). Tal es así que, sin una cooperación eficaz entre los órganos designados a tal efecto por cada Estado, el derecho alimentos podría quedar frustrado en muchas ocasiones.

\section{BIBLIOGRAFÍA}

ÁLVAREZ GONZÁLEZ, S. (1996). Crisis matrimoniales internacionales y prestaciones alimenticias entre cónyuges. Madrid: Civitas.

AZCÁRRAGA MONZONÍS, C. (2008). "El nuevo Convenio de La Haya sobre el cobro internacional de alimentos para los niños y otros miembros de la familia" REDI, LX, I, pp. 491-522.

BORRÁS RODRÍGUEZ, A. (2008). "La cooperación internacional de autoridades: en particular el caso del cobro de alimentos en el extranjero", AEDIPr., t. VII, pp. 129 y ss.

CARAVACA, A. L. y CARRASCOSA GONZÁLEZ, J. (2014). Derecho Internacional Privado, Vol. I. Granada: Comares. 
CARBALLO PIÑEIRO, L. (2001). "Competencia judicial internacional y modificación de prestaciones de ejecución continuada: más allá de la STC 61/2000", AEDIPr, t. I, pp. 463-482.

ESPINOSA CALABUIG, R. (2007). Custodia y visita de menores en el espacio judicial europeo. Barcelona: Marcial Pons.

ESPINOSA CALABUIG, R. (2009). "Obligaciones alimenticias hacia el menor y su relación con la responsabilidad parental", en M. C. Baruffi y R. Caffari Panico. Le nuove competenze comunitarie. Obbligazioni alimentari e successioni. Papua: Cedam, pp. 51-110.

ESPLUGUES MOTA, C. (2014). "Lección 16. Alimentos", en J. L. Iglesias Buhigues y C. Esplugues Mota. Derecho internacional privado. Valencia: Tirant lo Blanch.

FERNÁNDEZ ROZAS, J.C. y SÁNCHEZ LORENZO, S. (2013). Derecho internacional privado. Madrid: Civitas.

GARCIMARTÍN ALFÉREZ, F. (2012). Derecho internacional privado. Madrid: Cizur Menor, Civitas Thomson Reuters.

MICHINEL ÁLVAREZ, M. A. (2002). "La sentencia extranjera ante el cambio de circunstancias (con especial referencia a la condena de prestación periódica de alimentos)", REDI, vol. LIV, 2: 641-668.

PARRA RODRÍGUEZ, C. (2010). "La obligación de alimentos para los menores: nuevas soluciones desde el Derecho internacional privado", en F. Aldecoa Luzárraga y J. Forner Delaygua (dirs.). La protección de los niños en el Derecho internacional y en las Relaciones internacionales. Madrid: Marcial Pons/Colegio notarial de Cataluña, pp.275-298.

POCAR, F. y VIARENGO, I. (2009). "Il regolamento (CE) $n^{\circ}$ 4/2009 in materia de obbligazioni alimentari”, Riv.dir.int.priv.proc., 4: 805 y ss.).

VIARENGO, I. (2007). "Le obbligazioni alimentari nel diritto internazionale privato comunitario", en Bariatti, S. La famiglia nel diritto internazionale privato comunitario. Milán, pp. 227 y ss.

VIRGÓS SORIANO, M. y GARCIMARTÍN ALFÉREZ, F. (2007). Derecho procesal civil internacional. Litigación internacional. Madrid: Cizur Menor.

\section{Breve currículo:}

\section{Rosa Lapiedra Alcamí}

Profesora de Derecho internacional privado en la Facultad de Derecho de la Universitat de València (España) y Doctora en Derecho por este mismo Centro. Ha impartido clases de Derecho internacional privado, derecho de familia y comercio internacional tanto en Grado como en Postgrado en la Universitat de València y en la Universidad Jaume I de Castellón (España). Asimismo, ha sido profesora visitante en la Universidad de Florianópolis (Brasil) y ha realizado numerosas estancias de Investigación en el Instituto de Estudios Legales Avanzados de Londres (IALS). Desde el punto de vista práctico, ha estado trabajando en la Cámara de Comercio Internacional de París en la tramitación de arbitrajes comerciales internacionales. Ha participado en numerosos Proyectos de Investigación relacionados con el comercio internacional, derecho de familia, sustracción internacional de menores, derecho de la Unión Europea, etc. Actualmente dirige un módulo de Docencia Jean Monnet en materia de Derecho de familia y sucesiones en la Unión Europea. 